\title{
Medical Appropriateness of Hospital Utilization: an Overview of the Swiss Experience
}

\section{B. SANTOS-EGGIMANN, * F. PACCAUD* and T. BLANC $\ddagger$}

*University of Lausanne, Department of Social and Preventive Medicine, Lausanne, Switzerland

$\ddagger$ State of Vaud, Public Health Department, Lausanne, Switzerland

We present here the principal results of four concurrent hospital utilization reviews conducted in Switzerland in 1990 and 1991, based on an adapted Appropriateness Evaluation Protocol. The studies were performed on all the hospital days from a sample of patients admitted over a 6 month period. The level of inappropriate use ranged between 8 and $15 \%$ in terms of days and was consistently higher in medicine than in surgery. In comparison with other published studies, the low proportion of observed inappropriate days is probably due, at least partly, to differences in study design.

Key words: Hospitalization, utilization review, appropriateness.

\section{INTRODUCTION}

The Swiss health care system is organized at the state level for most of its aspects. Each of the 26 states is responsible for the organization of its hospital network. While some private clinics are entirely self-financed, the state public health department substantially contributes to the financing of the regional non-profit acute care hospitals. The law regulating the basic medical insurance contract is federal, and specifies a full reimbursement of acute care hospital stays. No co-payment was included in the law for acute care hospital stays until very recently. Additional costs for hospital stays in private clinics or divisions are paid by the patient either out-ofpocket or through complementary insurance contracts not covered by this law. There are very few financial incentives for individuals to avoid unnecessary hospital days in the regional hospitals, since virtually every resident has been covered in recent years by medical insurance; and while patients do not contribute to acute care hospital costs (except through taxes and insurance premiums), a co-payment is required for all other types of care (ambulatory care, chronic care, long-term care).

Hospital utilization reviews based on Gertman and Restuccia's Appropriateness Evaluation Protocol (AEP) [1] in Switzerland were conducted in non-profit acute care hospitals of the State of Vaud in the early 1990s. The State of Vaud is organized into eight health areas; in each area a non-profit hospital, subsidized based on a global prospective payment system, is the regional reference center. Such hospitals shelter at least emergency, medicine, surgery, gynaecology, obstetrics and paediatrics departments. In addition, speciality (ophthalmology, etc.) departments are available in some of them. Non-profit hospitals accounted for $80 \%$ of acute care hospital beds in 1991, and private clinics for $20 \%$. The first review took place during the first semester of 1990 in the St-Loup/ Orbe Hospital [2], as one of three specific interventions in regional non-teaching hospitals aimed at reducing the length of stay, and was sponsored by the state public health department

Submitted 6 April 1995; accepted 31 May 1995.

Correspondence: B. Santos-Eggimann, MD, MPH, DrPH, Institut Universitaire de Médecine Sociale et Preventive, 17 rue du Bugnon, CH-1005 Lausanne, Switzerland. Tel: (+41) 213132020 ; Fax (+41) 213132035.

(Swiss collaboration to the BIOMED project No. BMH1-CT93-1053 on Appropriateness of hospital use) 
to promote hospital performance. Medical insurance companies co-sponsored the research.

In 1989, St-Loup/Orbe was a 199 acute care bed hospital with medicine, surgery, gynaecology, obstetrics and paediatrics departments. It was characterized by an average length of stay of 10.4 days and a low occupancy rate $(60 \%)$. The main purposes of the review were to develop/adapt and test an instrument allowing detection of inappropriate days and their causes, and act upon them in order to decrease inappropriate use without affecting the quality of care and through a close collaboration between the hospital and the public health department. Three other regional hospitals (Aigle, Payerne and Yverdon) joined the study in 1991 and independently performed a six-month review; design and instrumentation were similar in all the reviews which were coordinated and supervised by the public health department of the State of Vaud. The following overview summarizes the main features and results of the four reviews [3-5].

\section{METHODS}

All four reviews were performed concurrently in order to promote an exchange of information between the hospital staff and the "reviewer" during the patient's stay, and were based on the same methodology and instrumentation. The goal was to obtain better information for decision-making on appropriateness, as compared to retrospective studies, and the emphasis was on information exchange in order to reduce the length of stay rather than on evaluation and comparison with other hospitals. As a preliminary step, the AEP was adapted to local needs and circumstances in the St-Loup/Orbe Hospital. The 1981 AEP was submitted to, and modified by, the physicians in charge of the departments, and then tested for acceptability. The main changes were the adoption of a single list of criteria for admission and subsequent days of care, motivated by the concurrent design of the review. Little information may be recorded in patient's files during the admission day, making a retrospective review difficult. The original AEP addressed this issue with a shorter list of criteria for the admission day. In a concurrent design, additional infor- mation can be obtained through interviews with hospital teams and consequently there is no need for a shorter list of criteria. The final list included 24 criteria in three categories: medical care, paramedical care, and health statusrelated (Appendix). Stays characterized by an inappropriate admission day were not eliminated since the admission day may be inappropriate (e.g. investigations postponed to the next day) and subsequent days appropriate. The override option was maintained and required a consensus between the reviewer and the physician in charge of the patient. Every medically inappropriate day, according to this modified AEP, was then investigated in light of Selker's Delay Tool [6], which was also translated in French, modified and reorganized into nine major categories.

Reviewers were physicians or a nurse (in one setting) hired by the hospital. In each hospital, the reviewer had access to a review committee, which included heads of administrative, medical and nursing sectors, who approved the medical criteria and helped to resolve situations were the reviewer and the hospital physician to disagree on an override. This never happened.

A random sample of at least $50 \%$ of all admissions was selected for review in each hospital. In three settings, transfers between departments were not considered as new admissions. Each day of stay of the selected patients was reviewed. The reviewer had access to the patient's file and obtained additional information through interviews with staff members within $24 \mathrm{hr}$ at least of admission, each day when the results of complementary examinations were due, and at least once a week. The review covered the medicine, surgery, orthopaedics and gynaecology departments in all hospitals, but data were not analysed separately for surgical and orthopaedic patients in most of them (Table 1). In the St-Loup/Orbe experience, a data summary was periodically provided to the hospital departments in order to promote corrective mechanisms.

The observed days of stay are clustered (all the days of a patient are included) and, hence, cannot be analysed as independent observations. For this reason, the computation of $95 \%$ confidence intervals is limited to the estimation of the proportion of stays with at least one inappropriate day in each hospital. 
TABLE 1. Departments under review in four hospitals

\begin{tabular}{lcccccc}
\hline & \multicolumn{6}{c}{ Department } \\
\cline { 2 - 7 } Hospital & Medicine & Surgery & Orthopaedics & Gynaecology & Paediatrics* & Others $¥$ \\
\hline SL/Orbe & $\mathrm{X}$ & $\mathrm{X}$ & $\ldots \ldots \ldots$ X & $\mathrm{X}$ & $\mathrm{X}$ & \\
Aigle & $\mathrm{X}$ & $\mathrm{X}$ & $\mathrm{X}$ & $\mathrm{X}$ & & $\mathrm{X}$ \\
Payerne & $\mathrm{X}$ & $\mathrm{X}$ & $\ldots \ldots \ldots$ X & $\mathrm{X}$ & $\mathrm{X}$ & $\mathrm{X}$ \\
Yverdon & $\mathrm{X}$ & $\mathrm{X}$ & $\ldots \ldots \ldots$ X & $\mathrm{X}$ & & \\
\hline
\end{tabular}

* Paediatric AEP used in Payerne Hospital.

$\ddagger$ Ear, nose, throat, urology and ophthalmology.

..... - Aggregated in analyses.

TABLE 2. Length of stay and percentage inappropriate admissions and days in four hospitals

\begin{tabular}{lcccccc}
\hline Hospital & $\begin{array}{c}\text { Number of } \\
\text { reviewed } \\
\text { stays }\end{array}$ & $\begin{array}{c}\text { Number of } \\
\text { reviewed } \\
\text { days }\end{array}$ & $\begin{array}{c}\text { Mean } \\
\text { length } \\
\text { of stay } \\
\text { (days) }\end{array}$ & $\begin{array}{c}\text { Inappropriate } \\
\text { admissions } \\
(\%)\end{array}$ & $\begin{array}{c}\text { Inappropriate } \\
\text { days } \\
(\%)\end{array}$ & $\begin{array}{c}\text { Corrected } \\
\text { length } \\
\text { of stay* } \\
\text { (days) }\end{array}$ \\
\hline SUOrbe & 782 & 7391 & 9.5 & 6.0 & 12.7 & 8.6 \\
Aigle & 801 & 7853 & 9.8 & 4.2 & 11.2 & 8.8 \\
Payerne & 1645 & 16,176 & 9.8 & 1.3 & 8.3 & 9.0 \\
Yverdon & 1081 & 10,197 & 9.4 & 2.7 & 15.3 & 8.1 \\
\hline
\end{tabular}

*(Total number of days-inappropriate days)/(total number of admissions-entirely inappropriate stays).

\section{RESULTS}

The level of inappropriate hospital use ranged between 8.3 and $15.3 \%$ for days, and $1.3-6.0 \%$ for admissions (Table 2). In spite of their low frequency, inappropriate admissions accounted for a sizeable proportion of the total number of inappropriate days, between 14.3 and $27.3 \%$. Overall, the proportion of partly or entirely (from the first to the last day) inappropriate stays varied between 9.6 and $28.6 \%$ (Table 3). The length of stay, corrected for inappropriate use, was similar in the four hospitals (means $8.1-9.0$ days), and was $0.8-1.3$ days lower than the observed mean length of stay of the participating hospitals.

While the proportion of inappropriate days was not very different between the hospitals, Tables 4 and 5 show that the level of inappropriateness was consistently found higher in medicine $(14.4-24.8 \%)$ than in surgery (4.6$10.4 \%$ ). Most of the days under review (more than $85 \%$ and up to $96 \%$ ) were spent in the medicine or surgery departments. The hospitals characterized by the highest and the lowest levels of inappropriateness in the medicine de- partment also ranked at the two extremes for their surgical department.

In each review, the classification of causes for inappropriate days showed a clear predominance of delays in discharge planning, responsible for $52-82 \%$ of the inappropriate days recorded (Table 6). The second major cause was associated with medical decisions and more precisely related to the politically difficult decision to deny an unnecessary admission requested by another physician.

\section{COMMENTS AND PERSPECTIVES}

The level of inappropriate use was low in the four participating acute-care hospitals in comparison with published results in other countries. However, such comparisons are biased by the differences in sampling and data collection procedures: most of these studies, generally performed in the USA, were based on a cross-sectional sample (one-day reviews) and on a retrospective data collection while a concurrent design with a sampling of stays rather than days was selected in the State of Vaud, 
TABLE 3. Proportion of stays with at least one inappropriate day, by hospital

\begin{tabular}{lcccc}
\hline Hospital & $\begin{array}{c}\text { Number of } \\
\text { inappropriate* } \\
\text { stays }\end{array}$ & $\begin{array}{c}\text { Number of } \\
\text { reviewed } \\
\text { stays }\end{array}$ & $\begin{array}{c}\text { Inappropriate* } \\
\text { stays } \\
(\%)\end{array}$ & $\begin{array}{c}95 \% \\
\text { Confidence } \\
\text { interval }\end{array}$ \\
\hline SLOrbe & 224 & 782 & 28.6 & {$[25.4 ; 31.8]$} \\
Aigle & 172 & 801 & 21.5 & {$[18.7 ; 24.3]$} \\
Payerne & 158 & 1645 & 9.6 & {$[8.2 ; 11.0]$} \\
Yverdon & 203 & 1081 & 18.8 & {$[16.5 ; 21.1]$} \\
\hline
\end{tabular}

* Entirely or partially inappropriate stay (at least one inappropriate day).

TABLE 4. Length of stay and percentage inappropriate admissions and days in the department of medictne of four hospitals

\begin{tabular}{lccccc}
\hline & $\begin{array}{c}\text { Number of } \\
\text { reviewed } \\
\text { stays }\end{array}$ & $\begin{array}{c}\text { Number of } \\
\text { reviewed } \\
\text { days }\end{array}$ & $\begin{array}{c}\text { Mean } \\
\text { length } \\
\text { of stay } \\
\text { (days) }\end{array}$ & $\begin{array}{c}\text { Inappropriate } \\
\text { admissions } \\
(\%)\end{array}$ & $\begin{array}{c}\text { Inappropriate } \\
\text { days } \\
(\%)\end{array}$ \\
\hline SL/Orbe & 307 & 3542 & 11.5 & 6.2 & 17.3 \\
Aigle & 364 & 4553 & 12.5 & 4.1 & 14.4 \\
Payerne & 429 & 5893 & 13.7 & 3.7 & 14.9 \\
Yverdon & 297 & 3738 & 12.6 & 6.4 & 24.8 \\
\hline
\end{tabular}

TABLE 5. Length of stay and percentage of Inappropriate admisslons and days in the department of surgery of four hospitals

\begin{tabular}{lccccc}
\hline & $\begin{array}{c}\text { Number of } \\
\text { reviewed } \\
\text { stays }\end{array}$ & $\begin{array}{c}\text { Number of } \\
\text { reviewed } \\
\text { days }\end{array}$ & $\begin{array}{c}\text { Mean } \\
\text { length } \\
\text { of stay } \\
\text { (days) }\end{array}$ & $\begin{array}{c}\text { Inappropriate } \\
\text { admissions } \\
(\%)\end{array}$ & $\begin{array}{c}\text { Inappropriate } \\
\text { days } \\
(\%)\end{array}$ \\
\hline SL/Orbe & 401 & 3577 & 8.9 & 6.0 & 8.8 \\
Aigle* & 256 & 2421 & 9.5 & 3.1 & 6.3 \\
Payerne & 878 & 8067 & 9.2 & 0.6 & 4.6 \\
Yverdon & 679 & 5895 & 8.7 & 15.0 & 10.4 \\
\hline
\end{tabular}

* Orthopaedics excluded.

TABLE 6. Dustribution of main causes of inappropriate days, by hospital

\begin{tabular}{lrrrr}
\hline & \multicolumn{5}{c}{ Hospital } \\
\cline { 2 - 5 } Cause (percent) & SLOrbe & Aigle & Payerne & Yverdon \\
\hline Discharge planning & 55.7 & 62.5 & 81.9 & 60.7 \\
Physician-related & 19.7 & 15.2 & 9.7 & 24.4 \\
Scheduling investigations & 11.7 & 11.6 & 1.9 & 4.8 \\
Waiting for surgery & 6.3 & 2.5 & 0.4 & 5.4 \\
Waiting for results of investigations & 3.5 & 0.5 & 0.8 & 0.5 \\
Expert opinion-related & 1.9 & 4.4 & 1.2 & 0.7 \\
Performing investigations & 1.0 & 1.5 & 1.3 & - \\
Patient/family-related & 0.3 & 1.8 & 2.8 & 3.4 \\
\hline Number of inappropriate days & 926 & 877 & 1341 & 1561 \\
\hline
\end{tabular}

* Paediatrics excluded. 
where the emphasis was more on determining a precise estimate of inappropriate use for the local hospitals, collecting extensive information on causes, and using this information for improvement, than on comparing inappropriate use between hospitals. This choice leads to an estimate of the level of inappropriateness constrained by the relationship that may link the consecutive days of a given stay. The issue of comparability between the estimates of the level of inappropriateness, resulting from retrospective and concurrent designs, requires investigation. Retrospective data collections are likely to overestimate the level of inappropriateness if records are not very detailed and comprehensive, particularly because the AEP requires only one single criterion to be present in order to validate a day. The low rate observed in the State of Vaud may also reflect changes induced in the hospital by a concurrent review designed in order to maximize interactions with the hospital staff. Unfortunately, the impact of the review on the level of inappropriateness was not evaluated. Other explanations, such as differences between the State of Vaud and other countries in the mix, types and availability of health services outside the hospitals, cannot be explored due to the lack of detailed information related to the health care environment in published utilization reviews.

A second limitation is the uncertain validity and reliability of the modified AEP. A reliability study conducted during the reviews in Aigle, Payerne and Yverdon hospitals [7] reported an agreement on the overall judgment of appropriateness for $88 \%$ of the days when the review was performed independently by the hospital reviewer and a reviewer hired by the public health department. The Kappa statistic, however, varied between a low 0.31 and a convincing 0.80 , and the specific agreement (defined as the proportion of agreement reached when at least one of the reviewers in a pair qualifies the day as inappropriate) ranged between 30 and $71 \%$. There is no available comparison of the original and the modified AEP applied to the same set of days.

These first reviews prompted other studies. In the State of Vaud, a fifth review was conducted in 1991, in the University-affiliated hospital, based on the original AEP (results unpublished). The St-Loup/Orbe Hospital has been performing a continuous concurrent review on a sample of its patients since September 1992, and a study was devoted to the targeting of the stays likely to include some inappropriate days, based on patient's characteristics at admission [8]. The State of Valais is on the way to generalizing the practice of hospital reviews in all subsidized acute care hospitals. A review is also under way in the University hospital of Geneva; of special interest, in both the University hospitals of Vaud and Geneva, is a comparison between the original AEP and selected information abstracted from routine hospital data sources, in order to define a lower-cost (marginal cost) concurrent monitoring system.

Acknowledgements: The work of the project on which this paper is based was supported by the European Union Grant BIOMED (BMH1 CT93 1053) awarded to the Mario Negri Institute, Milan, Italy.

\section{REFERENCES}

1. Gertman P M and Restuccia J D, The Appropriateness Evaluation Protocol: a technique for assessing unnecessary days of hospital care. Med Care 19(8): 855, 1981.

2. Winterhalter G, Blanc T and Kulczyki E, Importance et causes de l'utilisation inappropriée identifiée à l'Hópital de St-Loup. Service de la santé publique (Cah Rech Doc IUMSP), Lausanne, 1991.

3. Kalil C, Blanc $\mathrm{T}$ and Sidler $\mathrm{M}$, Importance et causes de l'utilisation inappropriée identifié à l'Hópital d'Aigle. Service de la santé publique (Cah Rech Doc IUMSP 84), Lausanne, 1992.

4. Burdet A, Perrin J C, Devaud M, Blanc T and Sidler M, Importance et causes de l'utilisation inappropriée identifiée à l'Hôpital de Payeme. Service de la santé publique (Cah Rech Doc IUMSP), Lausanne, 1991.

5. Boschung $D$ and Sidler $M$, Importance et causes de l'utilisation inappropriée identifiée à l'Hópital d'Yverdon-les-Bains. Service de la santé publique (Cah Rech Doc IUMSP 83), Lausanne, 1992.

6. Selker H P, Beshansky J R, Pauker S G and Kassirer J P, The epidemiology of delays in a teaching hospital: the development and use of a tool that detects unnecessary hospital days. Med Care 27(2): 112, 1989.

7. Santos-Eggimann B, Hospital utilization reviews under field conditions: potential and improvements. Int J Technol Assess Health Care 9(4): 514, 1993.

8. Blanc T, Predicting inappropriate hospital use for 
focused concurrent utilization review (Master's Thesis). University of Washington, Seattle, 1993.

\section{APPENDIX: REVISED APPROPRIATENESS EVALUATION PROTOCOL}

\section{List of criteria}

(Commentary available upon written request to author)

\section{Criteria linked to medical procedures}

1. Surgical procedure fulfilling at least one of the conditions listed in commentary.

2. Paramedical investigation fulfilling at least one of the conditions listed in commentary.

3. Treatment requiring frequent dose adjustments under direct medical supervision.

4. Patient requiring close medical monitoring by a doctor at least twice a day.

\section{Criteria linked to paramedical services}

5. Admission to intensive care unit (including cardiac monitoring and artificial respiration).

6. Respiratory care, administration of oxygen, CPPB, IPPB and intensive respiratory therapy.

7. Parenteral therapy (medication, electrolytes, fluids, protein).

8. Chemotherapy lasting more than one day.

9. Intramuscular and/or subcutaneous injections at least three times a day when ambulatory care or transfer to another type of establishment is impossible.
10. Treatment of major surgical or traumatic wound, including care of surgical site, and/or presence of drains or catheters (except permanent urinary catheters).

11. Fluid balance assessment.

12. Patient requiring close clinical monitoring by a nurse at least three times a day, according to written medical prescription.

13. Intensive physiotherapy at least b.i.d. with daily medical monitoring, including strict bedrest and progressive mobilization when ambulatory care or transfer to another type of establishment is impossible.

III. Criteria linked to health status of patient

14. Cardiac frequency $<50 / \mathrm{min}$ or $>140 / \mathrm{min}$.

15. Blood pressure: systolic $<90$ or $>200 \mathrm{~mm} \mathrm{Hg}$ and/or diastolic $<60$ or $>120 \mathrm{~mm} \mathrm{Hg}$.

16. Severe and/or symptomatic abnormality of a blood test, electrolytes or blood gases; symptomatic acute metabolic disorder, acute aggravation of a chronic metabolic disorder.

17. Persistent fever with a minimum $38^{\circ} \mathrm{C}$ axillary temperature of at least 5 days duration or having appeared during hospitalization.

18. Recent acute confusional state.

19. Other acute, or recently aggravated neurological disorder.

20. Documented, new acute myocardial infarction.

21. Acute abdominal pain of undetermined origin.

22. Obstructive or paralytic ileus.

23. Active blood loss.

24. Attempted suicide (until condition allows psychiatric treatment). 